\title{
Geometric parameters of the apical meristem and the quality of phyllotactic patterns in Magnolia flowers
}

\author{
Danuta Wiss, Beata Zagórska-Marek* \\ Institute of Experimental Biology, Wrocław University, Kanonia 6/8, 50-328 Wrocław, Poland
}

\begin{abstract}
The ratio of primordium size to the meristem size $(P / M$ ratio) is regarded by some geometrical models of phyllotaxis as the parameter, which determines the quality of spiral and whorled patterns of lateral organ arrangement. This assumption was tested on floral meristems in four genets representing four Magnolia taxa: M. $\times$ salicifolia, M. stellata, M. denudata and M. acuminata. In successive zones of Magnolia flower, lateral organs are initiated in specific phyllotactic patterns and at specific values of the meristem and primordia sizes. The elements of perianth, usually positioned in three trimerous whorls, are initiated as large primordia on relatively small meristem. The switch in the identity of primordia, from tepals to stamens is accompanied by an abrupt increase in the size of the meristem and decrease in the primordia size. Small values of $P / M$ ratio and frequent occurrence of qualitative transformations of phyllotaxis contribute to the exceptionally rich spectrum of spiral patterns in androecium zone. New spiral patterns emerge when bigger primordia of carpels are initiated on the meristem, which at the same time starts diminishing in size either abruptly (M. $\times$ salicifolia, M. stellata, M. acuminata) or slowly ( $M$. denudata). Spiral patterns identified in gynoecia have lower numbers of parastichies than the patterns of androecia and occur in frequencies specific for the genet. Although noted ranges of the meristem and primordia sizes, justify the occurrence of phyllotactic patterns observed in successive zones of Magnolia flower, they do not explain genet-specific frequencies of the patterns observed in gynoecium zone. The lack of straightforward relationship between frequency of the patterns and $P / M$ ratio in gynoecium suggests that more complex geometrical factors or factors of non-geometrical nature are engaged in determination of Magnolia floral phyllotaxis.
\end{abstract}

Keywords: floral phyllotaxis, Magnolia, flower, organography, apical meristem, patterning, plant development

\section{Introduction}

Architecture of the aerial parts of plant is determined in the shoot apical meristem generating primordia of leaves, flowers and floral organs in regular phyllotactic patterns. In higher plants shoot apical meristem is organised into central zone with stem cells contributing to the meristem self-renewal and providing cells, which give rise to the internal tissues of the stem in the meristematic rib zone and cells incorporated into primordia in the peripheral zone. While self-perpetuating ability of the meristem allows preserving its general size and shape, initiation of primordia leads to cyclical changes of the meristem size during plastochrone - from minimal at the primordium inception to maximal just prior to the emergence of the next primordium. The size and shape of primordia are defined by the number of founder cells sequestered into

*Corresponding author. Email: beata@biol.uni.wroc.pl

This is an Open Access digital version of the article distributed under the terms of the Creative Commons Attribution 3.0 License (creativecommons.org/licenses/by/3.0/), which permits redistribution, commercial and non-commercial, provided that the article is properly cited. primordia and subsequent polarization and rate of their growth and proliferation. Geometrical features of the meristem and primordia are regarded by some theoretical models as the most important determinants of phyllotactic pattern quality [1-5] [see also Iterson (1907; cited in [5])]. However, some data suggest that the order, in which primordia are initiated on the meristem, is determined by yet undefined signal emanating from differentiated tissues in the stem [6-9].

Several numerical and geometrical rules can be applied to the identification and description of phyllotactic patterns, what allows discerning their two major categories - whorled and spiral patterns. Whorled patterns result from simultaneous initiation of two or more lateral organs at the same level of the meristem in such a way, that elements of successive whorls can be connected along vertical, parallel lines called ortostichies. The number of ortostichies is always double in relation to the merosity, which express the number of organs initiated per whorl. In spiral phyllotactic patterns lateral organs are connected by spiral lines, i.e. parastichies winding either clockwise (chirality S) or counterclockwise (chirality Z). Among several discernable sets of parastichies two, interesting each other at the angle closest to $90^{\circ}$ are the most conspicuous. Their numbers, often denoted as $\boldsymbol{m}: \boldsymbol{n}$, constitute so called expression of the pattern and correspond to two successive terms of mathematical phyllotactic sequence, in which every term can be derived from the sum of the previous two. The 
most often encountered expressions belong to the Fibonacci sequence $1,2,3,5,8,13, \ldots$ but may also belong to Lucas sequence $1,3,4,7,11, \ldots$ or any other. Various phyllotactic sequences representing numbers of parastichies in sets of alternating $S$ and $\mathrm{Z}$ chiralities, start with different terms what guarantees that any expression can be assigned only to one, unique pattern. Hence, every spiral pattern can occur in many of various possible expressions, which adopt one of two alternative chiral configurations. The chirality of the pattern is determined by the chirality of the first term in the phyllotactic sequence, which is related to imaginary line known as ontogenetic spiral. The number of ontogenetic spirals is the basis of further sub-categorization of spiral patterns into monojugies and multijugies. While in monojugate spiral patterns all primordia can be connected by single ontogenetic spiral, two or more are necessary in multijugate patterns and respectively two or more primordia are initiated at the same level of the meristem. For example, main Fibonacci bijugy with parastichies numbers belonging to the series $2,4,6,10,16, \ldots$ represents multijugy with two ontogenetic spirals and two primordia initiated at consecutive levels of the meristem.

Phyllotactic patterns of vegetative and generative structures play important role in plant classification and tend to be more constant for low rank taxonomic groups. Additionally, in the vast majority of higher plants we observe Fibonacci numbers of spirals in vegetative development, or Fibonacci numbers of organs in floral whorls - pentamerous in dicotyledons and trimerous in monocotyledons. Nonetheless, variability of phyllotaxis can be sometimes noted even in taxa representing low levels of taxonomic hierarchy, what is exemplified by intraspecific variation of patterns in vegetative shoots of Abies balsamea [10], in inflorescences of Carlina acaulis [11] or in flowers of Magnolia acuminata [12]. Diversity of spiral patterns can be especially spectacular in ancient flowers of magnolids with high number of floral organs [13], e.g. Michelia fuscata [14] and Drimys winteri [15]. Among such plants Magnolia stands out, exhibiting considerable species- or even genetspecific diversity of phyllotaxis in gynoecia [12].

Variability of patterns stems not only from their different spectra in different taxa in comparable stages of development but also from the fact, that phyllotactic patterns can quantitatively or qualitatively transform during ontogeny of a single plant $[16,17]$. Quantitative transformations occur through the increase or decrease in the number of parastichies within the same phyllotactic sequence and are quite common. Qualitative transformations result from changes in parastichies numbers bringing up the transition from one phyllotactic pattern to the other. In plant ontogeny qualitative transformations occur often together with the change in the phase of development, but only rarely within organs of the same identity [10,12,18-20].

Substantially much is already known about molecular mechanism governing primordia initiation on the meristem. It was demonstrated in series of experiments that auxin transport, dependent on subcellular localization of auxin efflux and influx carriers within meristematic L1 layer, plays the central role in this process [21-23]. Nonetheless we still do not know why some plants initiate organs in uniform and stable phyllotaxis while others exhibit more or less diverse patterns of organ arrangement. Many theoretical models of phyllotaxis try to address that problem by use of computer simulations reproducing creation of patterns during plant development [24-31]. All these models are consistent with Snow and Snow concept [32-34], which implicate that organ arrangement is a consequence of spatial influence which older primordia exert on newly initiated ones. Considering that primordia of definite size simply form in the first available space on the meristem surface, this concept suggests that the quality of phyllotactic pattern depends on the ratio of the primordia size to the size of the meristem $(P / M$ ratio). In whorled patterns primordia share equal space on the meristem circumference and the $P / M$ ratio is determined directly by the number of elements initiated

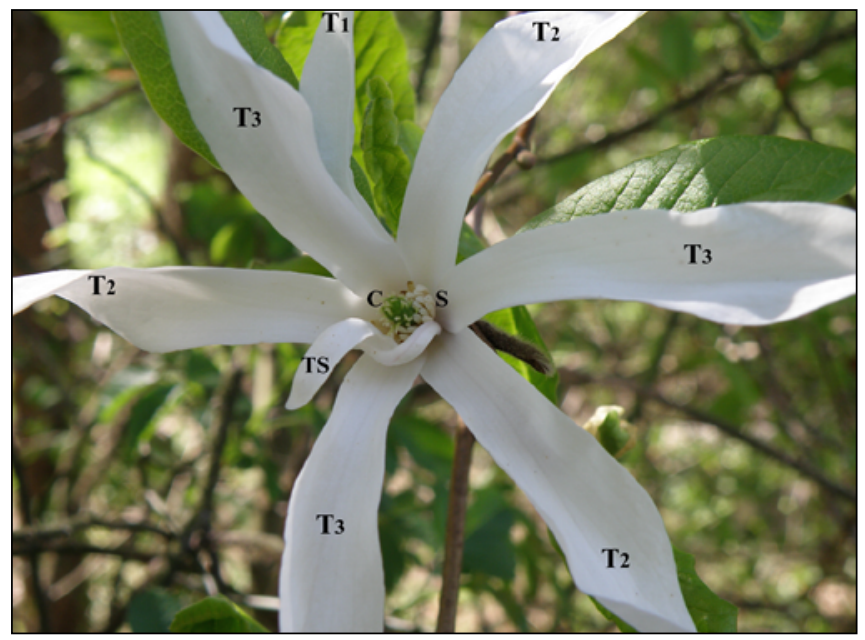

Fig. 1 M. stellata - an example of a typical structure of Magnolia flower. Only inner two of the three trimerous whorls of the perianth elements can be seen as complete. The large, narrow, white tepals, numbered increasingly in ontogenetic sequence, are followed here by one tepaloid stamen and then by small numerous stamens in androecium zone. The uppermost zone - the green gynoecium of cone-like appearance, is composed of many apocarpic carpels. In this young genet growing in Przecławice garden (not included into this study) tepalody is not yet fully expressed. C - carpels; $\mathrm{S}$ - stamens; $\mathrm{T}$ - tepals; TS - tepaloid stamen.

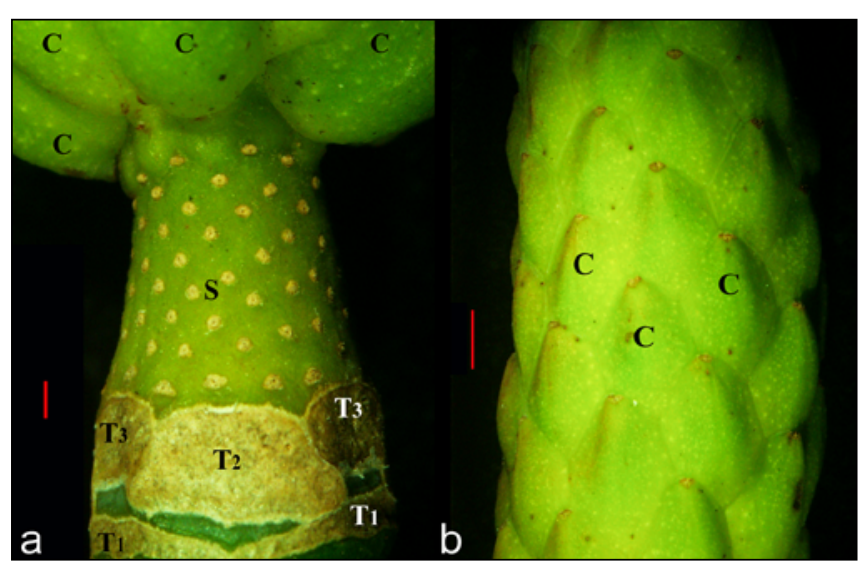

Fig. 2 M. acuminata - the axis of maturing generative shoot is clearly divided into distinct floral zones, as shown by the pattern of scars left by the floral parts, which fall off after blooming period. a Three regular trimerous whorls of tepal scars in the perianth zone and the spiral pattern of scars left by stamens on conical surface of androecium. b Ripening apocarpic ovaries arranged on cylindrical gynoecium in clear helical pattern, the lines connecting them (parastichies) winding up clockwise (S) or counterclockwise (Z) are easy to discern. C - ovaries; S - stamen scars; T - tepal scars. Scale bars (red): a $1 \mathrm{~mm}$; b $3 \mathrm{~mm}$. 
in the whorl. The relationship between the $P / M$ ratio and the quality of spiral phyllotaxis was first elucidated for idealised system of densely packed, circular primordia, distributed along parastichies intersecting at the right angle [1]. However, in the system with defined numbers of parastichies the value of $P / M$ ratio varies depending on the angle of parastichies intersection, which is determined by the shape of primordia or the way they pack on the meristem surface [2-4]. Consequently, every expression of any spiral pattern is characterised by a range of the $P / M$ ratio values rather than a single specific value of that parameter.

Geometrical models of phyllotaxis [1-5] [see also Iterson (1907; cited in [5])] suggest that spectra of patterns and their ontogenetic stability in the population of plants or lateral branches are under direct control of genetic mechanisms determining the size of the meristem and primordia. Molecular studies, focusing on Arabidopsis as a model plant, have revealed complexity of regulatory networks influencing geometrical parameters of the meristem. The WUS-CLV signalling loop was identified as the main genetic mechanism, which determines the meristem size through the control over the stem cell number in the central zone [35-37]. The size of the primordia founder cell poll is defined by gene ARGOS [38], but sequestration of these cells is accompanied also by repression of the genes $K N O X$, which specify meristematic state of the cells in the peripheral zone $[39,40]$. Data concerning subsequent proliferation and expansion of the primordia founder cells are still incomplete, although some components of the mechanisms underlying these processes have been characterized $[41,42]$. In addition, numerous studies have identified genetic factors which affect the meristem size specifically in generative phase of development [43-46] or influence both traits - the size of the meristem and primordia [47-49]. While wild type Arabidopsis plants have rather uniform, stable phyllotaxis in vegetative and generative development, mutations in most of the genes involved in the specification of the meristem and/or primordia size cause disorganisation of the pattern. Thus Arabidopsis, so well genetically defined, seems to be not suitable enough system for inquiries into the origins of phyllotactic diversity in plants.

In this paper we describe how geometric parameters of the meristem influence the quality of phyllotactic patterns in Magnolia flowers. Magnolia, exhibiting interspecific variability of phyllotaxis in gynoecia [12] and having different sizes of primordia of different identity [12,50,51], is the excellent model for this type of study. We focused on four different taxa - M. $\times$ salicifolia, M. stellata, M. denudata and M. acuminata, taking into account all three zones of the flower - perianth, androecium and gynoecium (Fig. 1, Fig. 2), to have a better view of developmentally changing floral phyllotaxis.

\section{Material and methods}

\section{Collection of the material}

Four taxa of Magnolia, each represented by one, individual tree (genet) were selected for this study: $M . \times$ salicifolia (hybrid of $M$. salicifolia and M. kobus), M. stellata (both growing in Botanical Garden of the University of Wrocław), M. denudata and M. acuminata (growing in Wrocław's public parks).

After short flowering period, which occurs in spring or early summer, depending on species and environmental conditions, floral buds emerge on lateral branches of Magnolia. Each newly formed bud contains apical meristem, which quickly initiates all primordia of floral organs, successively: tepals, stamens and carpels. During autumn and winter all initiated primordia and floral axis slightly elongate and differentiate into embryonic, generative shoot, which will fully develop in the next flowering season (Fig. 2). Both types of the material - meristems initiating organ primordia of different identity and embryonic generative shoots were collected in relevant seasons and examined.

\section{Identification of patterns}

Randomly collected floral buds containing meristems at the stage of initiation of either tepals, stamens or carpels were fixed in FAA (70\% alcohol, formaldehyde and acetic acid in ratio 9:0.5:0.5), dehydrated in ethanol series and embedded in paraffin. Buds were then sectioned transversally at 7-9 $\mu \mathrm{m}$ thickness and some of them also longitudinally (Fig. 3) at 5-7 $\mu \mathrm{m}$ thickness using Leica microtome. Sections were stained in safranine and fast green [52] and then photographed using Olympus BX50 light microscope connected with digital camera and "Silicon Graphics" workstation INDY. Sequence of the photomicrographs of the transverse sections from consecutive levels of a single floral bud enabled reconstruction of its content. Each reconstruction was represented by drawing of all initiated primordia mapped around central point of the meristem in plain, polar projection.

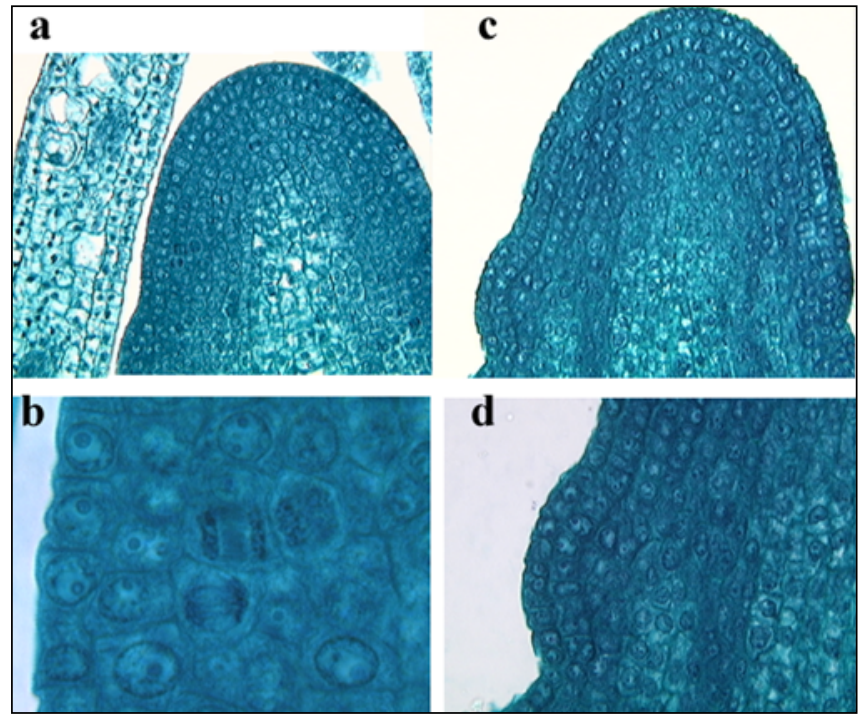

Fig. 3 a-d Longitudinal sections of two floral meristems of M. acuminata being at different stages of the youngest primordium initiation in gynoecium zone. $\mathbf{b}$ In magnified view of the lateral, organogenic zone of the apex (shown in a) the mitoses of the first periclinal divisions can be seen; they mark the onset of a new primordium, the formation of which surprisingly takes place well below the surface, covered by still flat two layers of tunica. d Swelling up primordium of the more advanced apex (shown in c) is already elevated, but still clearly covered by L1 and L2 layers.

Reconstructions were used for identification of phyllotactic patterns in the successive zones of the flower. The numbers $\boldsymbol{m}: \boldsymbol{n}$ of contact parastichies in two opposite sets of spirals, intersecting each other at the angle closest to $90^{\circ}$, were counted separately for each zone. The chirality of parastichies was also denoted, depending on direction of their winding from the base to the top of the zone, by index S (clockwise direction) 
or Z (anticlockwise direction). Alternate extrapolation of index $\mathrm{S}$ or $\mathrm{Z}$ from identified numbers of parastichies $\boldsymbol{m}: \boldsymbol{n}$ to the first number in corresponding phyllotactic sequence, allowed determining chiral configuration of the pattern. Method adapted for identification of patterns on a meristem, although precise, limited the examination to small sample of 19-34 buds per tree. Thus the study of phyllotaxis was extended over material extracted from autumn and winter buds, where the early processes of growth and determination do not affect the arrangement of carpels. Identification of phyllotactic patterns in gynoecium zone of embryonic shoots was done under binocular, by counting the numbers of contact parastichies.

\section{Floral meristem measurements and calculation of parameter $A$}

Meristem circumference $(M)$ and its arc occupied by primordium $(P)$ were measured on photomicrographs taken at the level of the meristem where the last initiated primordium had the widest transversal dimension. Measurements were performed using MapInfo Professional 6.5SCP. In this way the range of most probable values of parameter $P$ and $M$ was identified for successive flower zones, taking into account mean values and standard deviation. The variation of parameters $P$ and $M$ was expressed as coefficients of variation $(V)$. Knowing the ratio of parameter $P$ and $M$ we could calculate angular value of the meristem arc occupied by primordium (parameter $A$ ). According to Church [1] the value of parameter $A$ for any pattern expression $\boldsymbol{m}: \boldsymbol{n}$, at right angle $\beta$ of parastichies intersection can be determined using equation:

$$
A=360^{\circ} \sqrt{m^{2}+n^{2}}
$$

To calculate the value of parameter $A$ in the systems where angle $\beta$ is different than $90^{\circ}$ Church's equation was modified to the following form:

$$
A=360^{\circ} \sqrt{m^{2}+n^{2}}+/-2 m n \cos \beta
$$

In real systems with known phyllotactic patterns angles $\beta$ were determined by comparison of estimated values $A$ with theoretical values of that parameter, obtained on the basis of Equation (1) or (2) given above. The range of estimated values of parameter $A$ and values of angle $\beta$, compared with theoretical values of $A$, allowed us to predict the probability of occurrence of different patterns in the successive zones of the particular flower.

\section{Results}

\section{Perianth}

\section{PHYLLOTACTIC PATTERNS}

In all examined trees the first initiated elements of flower were typically three trimerous whorls of tepals (Fig. 1, Fig. 2, Fig. 4, Tab. 1). Unequal sizes and slightly asymmetric distribution of the elements of the whorl along meristem circumference suggested, that they were not always initiated simultaneously but sometimes in a very rapid spiral sequence.

Some exceptions from trimerous pattern of tepals were noted. In one bud of $M . \times$ salicifolia first two whorls were tetramerous, with four elements evenly distributed along the meristem circumference. Another rare modification was one element missing in the first whorl (noted in one M. stellata bud) and occurrence of two elements instead of one in the last whorl (noted in four M. $\times$ salicifolia buds). Microscopic

\begin{tabular}{|c|c|c|c|c|c|c|}
\hline Genet & Perianth & $N$ & Androecium & $N$ & Gynoecium & $N$ \\
\hline Magnolia $\times$ & $3: 3$ & 8 & - & - & - & - \\
\hline \multirow[t]{28}{*}{ salicifolia } & $3: 3^{*}$ & 1 & - & - & - & - \\
\hline & $3: 3$ & 20 & $7 s: 12 z$ & 1 & - & - \\
\hline & & & $7 z: 13 s$ & 1 & & \\
\hline & & & 8z:9s & 1 & & \\
\hline & & & 9z:11s & 1 & & \\
\hline & & & 9z:13s & 1 & & \\
\hline & & & $7 \mathrm{z}: 11 \mathrm{~s}$ & 1 & $4 s: 7 z$ & 4 \\
\hline & & & $7 \mathrm{~s}: 11 \mathrm{z} \triangleright 7 \mathrm{~s}: 9 \mathrm{z}$ & 1 & & \\
\hline & & & $8 \mathrm{z}: 11 \mathrm{~s} \rightarrow 7 \mathrm{z}: 11 \mathrm{~s}$ & 2 & & \\
\hline & & & $7 \mathrm{~s}: 11 \mathrm{z}$ & 1 & 4z:7s & 1 \\
\hline & & & $9 \mathrm{z}: 10 \mathrm{~s} \rightarrow 8 \mathrm{z}: 10 \mathrm{~s}$ & 1 & $5 s: 7 z$ & 1 \\
\hline & & & - $7 \mathrm{~s}: 8 \mathrm{z} \rightarrow 6 \mathrm{~s}: 7 \mathrm{z}$ & & & \\
\hline & & & $8 \mathrm{z}: 11 \mathrm{~s} \triangleright 8 \mathrm{z}: 9 \mathrm{~s}$ & 1 & $5 s: 8 z$ & 5 \\
\hline & & & $8 \mathrm{z}: 13 \mathrm{~s}$ & 1 & & \\
\hline & & & $9 \mathrm{z}: 12 \mathrm{~s} \triangleright 8 \mathrm{z}: 11 \mathrm{~s}$ & 1 & & \\
\hline & & & $9 \mathrm{z}: 12 \mathrm{~s} \rightarrow 8 \mathrm{z}: 12 \mathrm{~s}$ & 1 & & \\
\hline & & & $9 \mathrm{z}: 13 \mathrm{~s} \rightarrow 9 \mathrm{z}: 12 \mathrm{~s}$ & 1 & & \\
\hline & & & $>8 z: 9 s$ & & & \\
\hline & & & $7 \mathrm{z}: 9 \mathrm{~s} \triangleright 5 \mathrm{z}: 8 \mathrm{~s}$ & 1 & $5 z: 8 s$ & 4 \\
\hline & & & $7 z: 9 s \triangleright 5 z: 9 s \rightarrow 5 z: 8 s$ & 1 & & \\
\hline & & & $8 s: 13 z \rightarrow 8 s: 12 z$ & 2 & & \\
\hline & $3: 3^{*}$ & 4 & $10 \mathrm{z}: 11 \mathrm{~s} \rightarrow 9 \mathrm{z}: 11 \mathrm{~s}$ & 1 & $5 s: 8 z$ & 3 \\
\hline & & & $\rightarrow 8 \mathrm{z}: 11 \mathrm{~s}$ & & & \\
\hline & & & $10 \mathrm{z}: 12 \mathrm{~s} \rightarrow 9 \mathrm{z}: 12 \mathrm{~s}$ & 1 & & \\
\hline & & & $\rightarrow 9 \mathrm{z}: 11 \mathrm{~s} \triangleright 8 \mathrm{z}: 9 \mathrm{~s}$ & & & \\
\hline & & & $9 \mathrm{z}: 13 \mathrm{~s} \rightarrow 8 \mathrm{z}: 13 \mathrm{~s}$ & 1 & & \\
\hline & & & $8 \mathrm{~s}: 12 \mathrm{z} \triangleright 8 \mathrm{~s}: 10 \mathrm{z}$ & 1 & $5 z: 8 s$ & 1 \\
\hline & $4: 4 \rightarrow 3: 3$ & 1 & $10 \mathrm{z}: 13 \mathrm{~s} \triangleright 10 \mathrm{z}: 11 \mathrm{~s}$ & 1 & $6 z: 10 s$ & 1 \\
\hline
\end{tabular}

Tab. 1 Phyllotactic patterns of analysed magnolia genets.

\begin{tabular}{|c|c|c|c|c|c|c|}
\hline Magnolia & $3: 3$ & 2 & - & - & - & - \\
\hline \multirow[t]{26}{*}{ stellata } & $3: 3 \rightarrow 3 s: 5 z$ & 2 & - & - & - & - \\
\hline & $3: 3 s: 5 z \rightarrow \bullet 3$ & 1 & - & - & - & - \\
\hline & $3: 3 \rightarrow 4 \mathrm{z}: 5 \mathrm{~s}$ & 2 & - & - & - & - \\
\hline & $3: 3 \rightarrow 4 s: 5 z$ & 3 & $6 z: 8 s$ & 1 & - & - \\
\hline & & & $8 s: 14 z$ & 1 & - & - \\
\hline & & & $8 \mathrm{z}: 10 \mathrm{~s} \rightarrow \mathbf{8 z : 9 s}$ & 1 & - & - \\
\hline & $3: 3 \rightarrow 4 z: 5 s$ & 2 & $8 z: 12 s$ & 1 & - & - \\
\hline & & & $6 z: 11 s \rightarrow 6 z: 10 s$ & 1 & - & - \\
\hline & $3: 3 \rightarrow 5: 5$ & 1 & $8 s: 9 z$ & 1 & - & - \\
\hline & $3: 3 \rightarrow 3 z: 4 s$ & 2 & $9 \mathrm{z}: 10 \mathrm{~s} \triangleright 7 \mathrm{z}: 9 \mathrm{~s}$ & 1 & $6 z: 9 s \rightarrow 5 z: 8 s$ & 1 \\
\hline & & & $9 \mathrm{z}: 13 \mathrm{~s} \rightarrow 8 \mathrm{z}: 13 \mathrm{~s}$ & 1 & $5 \mathrm{~s}: 8 \mathrm{z}$ & 1 \\
\hline & $3: 3 \rightarrow 3 z: 4 s \rightarrow$ & 1 & $9 \mathrm{~s}: 9 \mathrm{z} \triangleright 7 \mathrm{~s}: 9 \mathrm{z} \triangleright 5 \mathrm{~s}: 8 \mathrm{z}$ & 1 & $5 s: 8 z$ & 1 \\
\hline & $3 z: 6 s$ & & & & & \\
\hline & $3: 3 \rightarrow 3 z: 5 s$ & 1 & $8 \mathrm{z}: 11 \mathrm{~s} \triangleright 8 \mathrm{z}: 9 \mathrm{~s} \triangleright 8 \mathrm{z}: 6 \mathrm{~s}$ & 1 & $5 s: 8 z$ & 1 \\
\hline & $3: 3 \rightarrow 4 z: 5 s$ & 3 & $6 z: 10 s$ & 1 & $6 z: 10 s$ & 1 \\
\hline & & & $7 \mathrm{~s}: 10 \mathrm{z} \rightarrow 7 \mathrm{~s}: 9 \mathrm{z}$ & 1 & $6 \mathrm{~s}: 9 \mathrm{z}$ & 1 \\
\hline & & & $9 \mathrm{~s}: 12 \mathrm{z} \rightarrow 9 \mathrm{~s}: 11 \mathrm{z}$ & 1 & $5 z: 8 s$ & 1 \\
\hline & $3: 3 \rightarrow 4 s: 5 z$ & 3 & $8 \mathrm{~s}: 13 \mathrm{z}$ & 1 & $5 z: 8 s$ & 2 \\
\hline & & & $7 \mathrm{z}: 11 \mathrm{~s}$ & 1 & & \\
\hline & & & $9 \mathrm{z}: 13 \mathrm{~s}>8 \mathrm{~s}: 11 \mathrm{z}$ & 1 & $5 s: 8 z$ & 1 \\
\hline & $3: 3 \rightarrow 5: 5$ & 4 & $8 s: 13 z \vdash 8 s: 10 z$ & 1 & $5 z: 8 s$ & 3 \\
\hline & & & $8 s: 13 z \rightarrow 8 s: 12 z>8 s: 5 z$ & 1 & & \\
\hline & & & $8 \mathrm{~s}: 13 \mathrm{z} \triangleright 8 \mathrm{~s}: 9 \mathrm{z}$ & 1 & & \\
\hline & & & $9 \mathrm{z}: 12 \mathrm{~s} \rightarrow 9 \mathrm{z}: 11 \mathrm{~s}$ & 1 & $5 \mathrm{~s}: 8 \mathrm{z}$ & 1 \\
\hline & & & > $8 \mathrm{z}: 10 \mathrm{~s}$ & & & \\
\hline & $3: 3 \rightarrow 5 s: 7 z$ & 1 & $7 \mathrm{~s}: 9 \mathrm{z}$ & 1 & $6 s: 9 z$ & 1 \\
\hline
\end{tabular}


Tab. 1 (continued)

\begin{tabular}{|c|c|c|c|c|c|c|}
\hline Genet & Perianth & $N$ & Androecium & $N$ & Gynoecium & $N$ \\
\hline Magnolia & $3: 3$ & 6 & - & - & - & - \\
\hline \multirow[t]{10}{*}{ denudata } & $3: 3$ & 13 & $8 \mathrm{z}: 12 \mathrm{~s}$ & 1 & - & - \\
\hline & & & $8 s: 13 z$ & 2 & - & - \\
\hline & & & $8 \mathrm{z}: 13 \mathrm{~s}$ & 3 & - & - \\
\hline & & & 10z:14s & 1 & - & - \\
\hline & & & $8 \mathrm{~s}: 12 \mathrm{z} \rightarrow 8 \mathrm{~s}: 13 \mathrm{z}$ & 1 & $5 z: 8 s$ & 3 \\
\hline & & & $8 s: 13 z$ & 2 & & \\
\hline & & & $10 \mathrm{~s}: 11 \mathrm{z} \triangleright 9 \mathrm{z}: 10 \mathrm{~s}$ & 1 & $6 z: 9 s$ & 2 \\
\hline & & & $\rightarrow 10 \mathrm{z}: 10 \mathrm{~s}$ & & & \\
\hline & & & $10 s: 15 z \triangleright 9 s: 13 z$ & 1 & & \\
\hline & & & $10 \mathrm{z}: 15 \mathrm{~s} \triangleright 10 \mathrm{z}: 9 \mathrm{~s}$ & 1 & $6 s: 10 z$ & 1 \\
\hline Magnolia & $3: 3$ & 10 & - & - & - & - \\
\hline \multirow[t]{13}{*}{ acuminata } & $3: 3$ & 15 & 9z:14s & 1 & - & - \\
\hline & & & $11 \mathrm{~s}: 12 \mathrm{z}$ & 1 & - & - \\
\hline & & & $11 \mathrm{~s}: 15 \mathrm{z}$ & 2 & - & - \\
\hline & & & $11 \mathrm{~s}: 14 \mathrm{z} \rightarrow \mathbf{1 1 s : 1 3 z}$ & 1 & - & - \\
\hline & & & $12 \mathrm{z}: 15 \mathrm{~s} \triangleright \mathbf{1 1 z}: 12 \mathrm{~s}$ & 1 & - & - \\
\hline & & & $8 s: 13 z$ & 3 & $5 z: 8 s$ & 3 \\
\hline & & & $9 \mathrm{z}: 15 \mathrm{~s} \triangleright 9 \mathrm{z}: 13 \mathrm{~s}$ & 1 & $4 z: 6 s$ & 1 \\
\hline & & & - 9z:11s & & & \\
\hline & & & $11 \mathrm{~s}: 12 \mathrm{z} \triangleright 10 \mathrm{~s}: 11 \mathrm{z}$ & 1 & 6z:9s & 1 \\
\hline & & & $11 \mathrm{~s}: 12 \mathrm{z} \triangleright 9 \mathrm{z}: 11 \mathrm{~s}$ & 1 & $4 s: 7 z \rightarrow 4 s: 6 z$ & 1 \\
\hline & & & $11 \mathrm{z}: 13 \mathrm{~s} \triangleright 9 \mathrm{z}: 10 \mathrm{~s}$ & 2 & $5 s: 8 z$ & 1 \\
\hline & & & & & $5 z: 7 s$ & 1 \\
\hline & & & $13 z: 14 s>9 z: 13 s$ & 1 & $4 z: 6 s$ & 1 \\
\hline
\end{tabular}

Patterns of successive zones of single meristem are arranged horizontally with final pattern underlined in bold type. Changes in phyllotactic patterns occurring as numerous transformations at the same level of the meristem, but in different sectors of its circumference are denoted by “ $\triangleright$ ", typical transformations by “ $\rightarrow$ ”. Asterisks mark the occurrence of two elements in place of one in the last whorl (“‘”) or lack of one element in the first whorl (“•"). $N$ - total number of particular patterns or transformations identified in successive zones of a flower.

analysis of $M . \times$ salicifolia meristem at the early stage of the initiation of such atypical whorl suggested, that the additional element could be created through unequal cleavage of primordium, which was initially much bigger than two other elements of the whorl.

In contrast to $M . \times$ salicifolia, $M$. denudata and $M$. acuminata, where initiation of perianth elements was always restricted to three whorls, in M. stellata tepalody occurred - the additional 5 to 16 tepals were initiated in places topologically corresponding to stamens (Fig. 1). These additional elements (tepaloid stamens) were arranged in different spiral patterns (Tab. 1).

\section{SIZE OF THE MERISTEM AND PRIMORDIA}

Small numbers of meristems initiating elements of perianth were found during collection of buds from each individual tree. The significant differences between minimal and maximal values of the meristem circumference $(M)$ and its arc occupied by primordium $(P)$ were noted between successive whorls and between examined genets (Fig. 5, Tab. 2). Those differences, underlined by high variation coefficients, could be only partially ascribed to natural variation. Meristems initiating large primordia, like in the perianth zone of Magnolia, are considerably smaller in the minimal phase of plastochrone just after the initiation than in the maximal phase - just prior to the initiation of the next primordium. The collection of the meristems in different phases of plastochrone and their small number undoubtedly influenced noted differences of the meristem and primordia sizes. Thus, the real extent to which the meristem and primordia changed their sizes between whorls, and in the case of M. stellata also after the switch to initiation of tepaloid stamens, could not have been properly estimated.

\section{Androecium}

\section{PHYLLOTACTIC PATTERNS}

The greatest diversity of phyllotactic patterns was noted in androecium zone of examined magnolias; 20 different patterns were identified in $M . \times$ salicifolia androecia $(N=25), 16$ in $M$. stellata $(N=21), 8$ in $M$. denudata $(N=13)$ and 13 in $M$. acuminata $(N=15)$. Besides well known patterns, like Fibonacci pattern (8:13) and its bijugy (6:10) or Lucas pattern (7:11), also various rare monojugies and multijugies were found in this zone (Fig. 4, Tab. 1). Numbers of parastichies expressing phyllotactic patterns were generally lower in $M . \times$ salicifolia and M. stellata than in M. denudata and M. acuminata (Fig. 4).

Whereas in the case of M. $\times$ salicifolia, M. stellata and M. acuminata the richness of phyllotaxis was so considerable that none of the patterns was recognised as dominating, in $M$. denudata the Fibonacci pattern was identified in the seven of thirteen examined buds. The great variability of phyllotaxis in androecia was clearly increased by the common occurence of qualitative transformations. Some of them were caused by dissapearence of single parastichy while others, what was very specific for androecium zone, by disappearence of multiple parastichies at the same level but at different points of the meristem circumference. In some cases, when transformations occured at two different levels of the meristem, even three phyllotactic patterns coexisted in one androecium (Tab. 1).

\section{SIZE OF THE MERISTEM AND PRIMORDIA}

The change in the identity of initiated primordia from tepals to stamens was accompanied by increase in the size of the meristem and decrease in the size of primordia. Similar numbers in opposite sets of parastichies in androecia of $M$. $\times$ salicifolia and $M$. stellata corresponded with similarity of geometrical parameters of the meristem. The mean values of parameters $M$ and $P$ in $M . \times$ salicifolia were equal to 939.18 $\mu \mathrm{m}$ and $65.05 \mu \mathrm{m}$ respectively, compared to $864.99 \mu \mathrm{m}$ and $65.69 \mu \mathrm{m}$ in M. stellata. Meristems of M. denudata and M. acuminata, which had higher numbers of parastichies had also apparently larger meristems (mean value of $M=1149.94$ $\mu \mathrm{m}$ for M. denudata and $1262.61 \mu \mathrm{m}$ for M. acuminata) and slightly larger primordia (mean value of $P=75.38 \mu \mathrm{m}$ for $M$. denudata and 70.32 for M. acuminata; Fig. 5, Tab. 2).

The broad range of low values of parameter $A: 20.35^{\circ}-30.23^{\circ}$ in $M . \times$ salicifolia, $21.96^{\circ}-34.35^{\circ}$ in $M$. stellata, $20.4^{\circ}-27.1^{\circ}$ in M. denudata and $16.77^{\circ}-23.77^{\circ}$ in M. acuminata (Tab. 3), together with high values of variation coeficients (Tab. 2), theoretically guaranteed wide spectra of phyllotactic patterns in androecia. Prevalence of Fibonacci pattern in M. denudata androecia was probably caused by the stability of angles $\beta$, which in every examined bud were equal or very close to $90^{\circ}$. Similarly, greater variability of phyllotaxis determined for $M$. × salicifolia than for M. stellata, was probably caused by a wider 

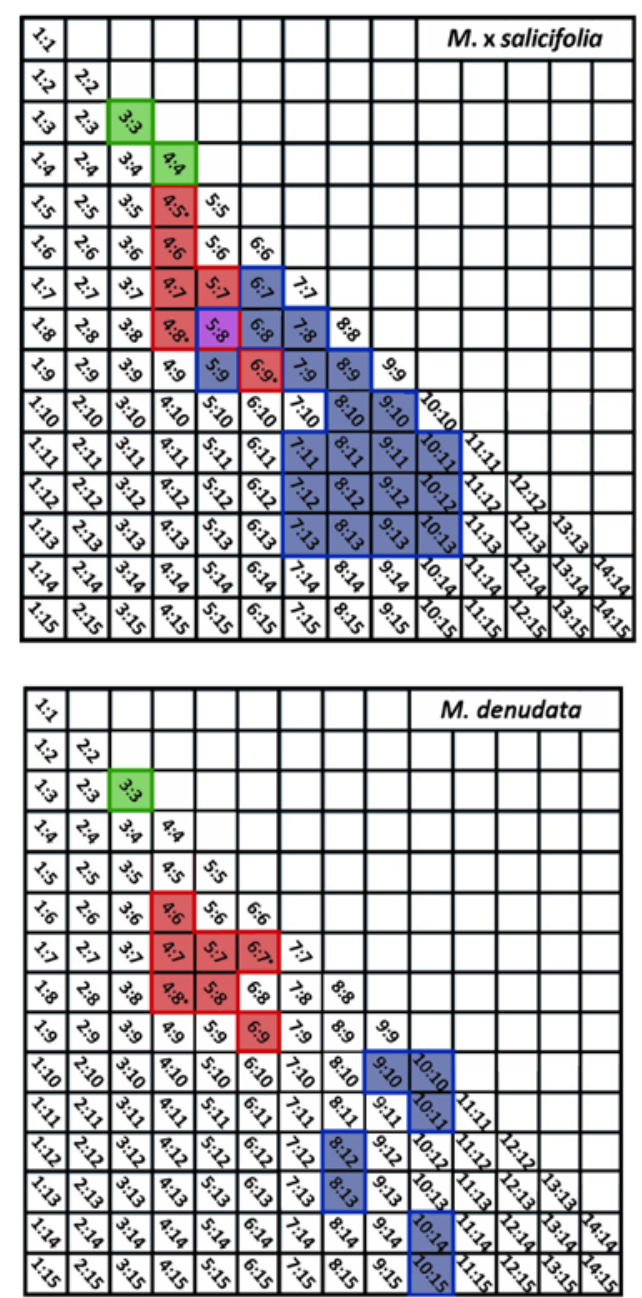
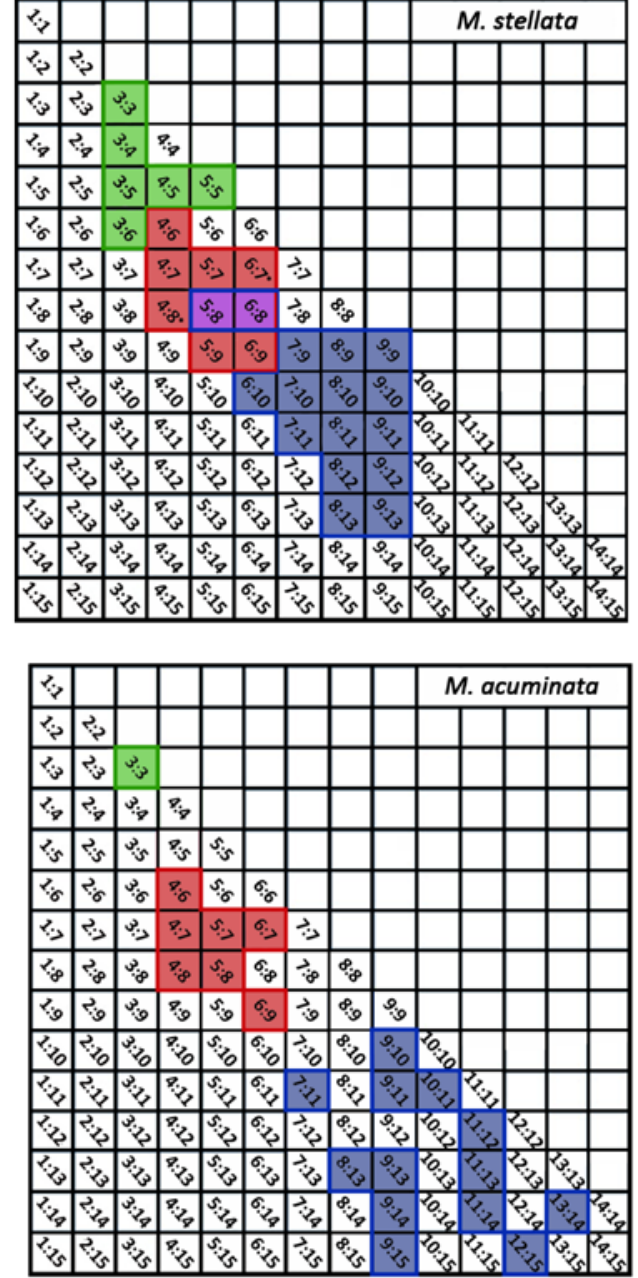

Fig. 4 Universal phyllotactic grids [12] presenting all $\boldsymbol{m}: \boldsymbol{n}$ phyllotactic patterns of analysed magnolias. Patterns of perianth, androecium and gynoecium are marked with green, blue and red colour respectively. Purple colour denotes patterns identified in gynoecia as well as androecia. Asterisks mark the patterns identified exclusively as involved in rare qualitative transformations in gynoecia, occurring either before or after the change in parastichy number.

range of estimated angles $\beta$ in the stamen zone of the later specimen $\left(60^{\circ}-105^{\circ}\right.$ in the case of $M . \times$ salicifolia compared to $75^{\circ}-90^{\circ}$ in M. stellata; Tab. 3).

\section{Gynoecium}

\section{PHYLLOTACTIC PATTERNS}

Analysis of phyllotaxis in Magnolia gynoecia had a very detailed character - in addition to the meristems also a large number of the embryonic, generative shoots was collected from each tree during autumn and winter. Shoots of M. $\times$ salicifolia, $M$. stellata and $M$. denudata were collected twice, during two successive seasons to check, whether the spectra of their patterns in gynoecium change seasonally. In $M . \times$ salicifolia shoots, only three pure patterns were identified: noticeably dominating Fibonacci pattern (83.54\% of 407 shoots and $83.52 \%$ of 261 shoots in two successive seasons), Lucas pattern as the second in frequency and Fibonacci bijugy as the most rare (Tab. 4). Fibonacci phyllotaxis dominated also in gynoecia of $M$. stellata $(90.09 \%$ of 111 shoots and $78.49 \%$ of 172 shoots in two successive seasons) and M. denudata (88.5\% of 87 and $85.53 \%$ of 159 shoots in two successive seasons). In M. stellata among 6 other patterns Fibonacci bijugy (6:10) was the second in frequency (Tab. 4), while in M. denudata all 4 additional patterns occurred in comparable frequency (Tab. 4). In the case of $M$. acuminata, the embryonic shoots were collected only during one season. Fibonacci pattern prevailed but occurred in slightly less than a half of the analysed shoots $(48.05 \%$ of 77 shoots in 2004), whereas among 6 other patterns some occurred in relatively high frequency $-5: 7$ and 4:6 (12.99\% each), 6:9 and 4:7 (11.69\% each; Tab. 4).

No major preference in the direction of the ontogenetic spiral was noted - numbers of generative shoots with configurations $S$ and $Z$ were similar within each phyllotactic pattern in all specimens (Tab. 4). Examination of the meristems (Tab. 1) revealed, that the patterns most frequent in gynoecium zone were initiated usually (5:8 and 4:7 in M. $\times$ salicifolia, 5:8 in $M$. stellata and M. acuminata) or exclusively (5:8 in M. denudata, and 4:6 in M. stellata) in continuity with the same pattern in androecium zone, whereas the rare patterns in gynoecium were preceded by qualitatively different but also uncommon androecium patterns.

In contrast to androecium zone qualitative transformations in gynoecium zone were not common - 13 transformations were identified in $M . \times$ salicifolia embryonic shoots, 9 in $M$. stellata and 3 in M. denudata (Tab. 4). No qualitative transformations were found during inspection of M. acuminata 
Tab. 2 Mean, minimal and maximal values of the meristem circumference and its arc occupied by primordium, standard deviation and variation coefficient in successive zones of examined flowers.

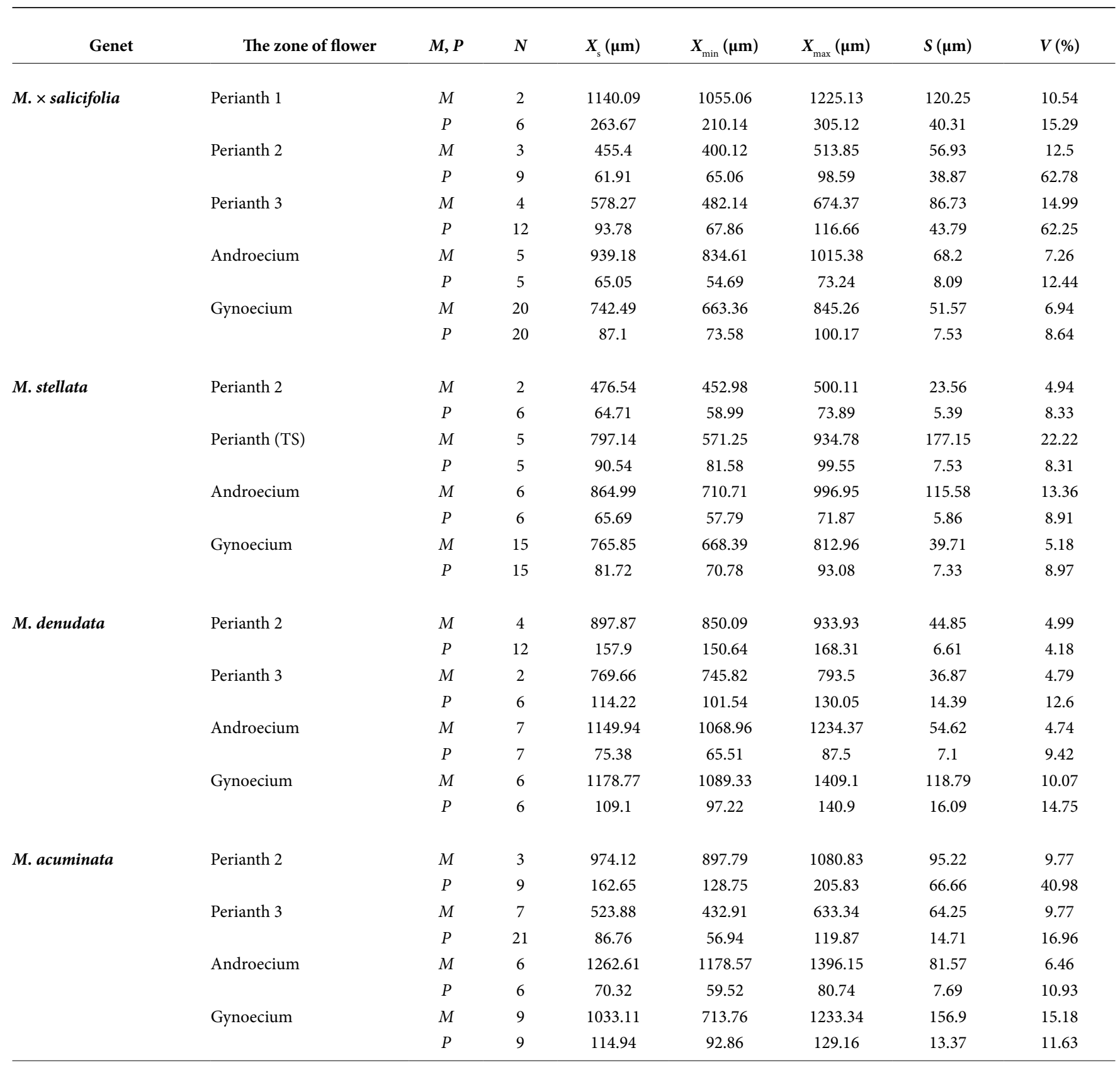

Terms perianth 1, 2, 3 and (TS) refer to the first, second and third whorl of the perianth and tepaloid sepals respectively. $M$ - meristem circumference; $P$ - meristem arc occupied by primordium; $S$ - standard deviation; TS - tepaloid sepals, $V$ - variation coefficient; $X_{\mathrm{s}}, X_{\max }, X_{\min }-\mathrm{mean}$, maximal and minimal values of $M, P, S$ and $V$, respectively.

embryonic shoots although on one of the meristems carpel arrangement changed from Lucas pattern into the main Fibonacci bijugy (Tab. 1). Transformations in the embryonic shoots occurred usually by disappearance of one parastichy, in few cases at two different levels of the system, e.g. in M. stellata $(5 \mathrm{~s}: 8 \mathrm{z} \rightarrow 5 \mathrm{~s}: 7 \mathrm{z} \rightarrow 4 \mathrm{~s}: 7 \mathrm{z})$ or M. denudata $(6 \mathrm{z}: 7 \mathrm{~s} \rightarrow 5 \mathrm{z}: 7 \mathrm{~s} \rightarrow 4 \mathrm{z}: 6 \mathrm{~s})$. Occasionally two parastichies were removed from the system at one point of the shoot circumference and in one case as many as three although not in the same set (transformation $5 \mathrm{z}: 8 \mathrm{~s} \rightarrow$ 4z:6s in M. $\times$ salicifolia). Transformation $5 \mathrm{~s}: 7 \mathrm{z} \rightarrow 5 \mathrm{~s}: 8 \mathrm{z}$ in $M$. denudata was exceptionally evoked by addition of the new parastichy to the existing set of parastichies (Tab. 4).

Some of identified transformations involved a very rare patterns. This enriched phyllotactic spectra of examined genets.
Patterns 6:7 and 4:8 in M. stellata and M. denudata and also 4:5, 4:8, 5:7 and 6:9 in $M . \times$ salicifolia were identified exclusively as associated with transformations (Fig. 4).

\section{SIZE OF THE MERISTEM AND PRIMORDIA}

After the switch from initiation of stamens to initiation of carpels, the size of primordia increases while meristem becomes smaller and eventually terminates after production of the last carpel. The number of organs in gynoecium differed between examined genets: $M . \times$ salicifolia initiated on the average 67 carpels (estimated for $N=18$ shoots), M. stellata 53 ( $N$ =13), M. denudata $68(N=10)$ and $M$. acuminata $39(N=7)$.

$M . \times$ salicifolia meristems were analysed at different stages between initiation of 11 th and 51st primordium (examined 

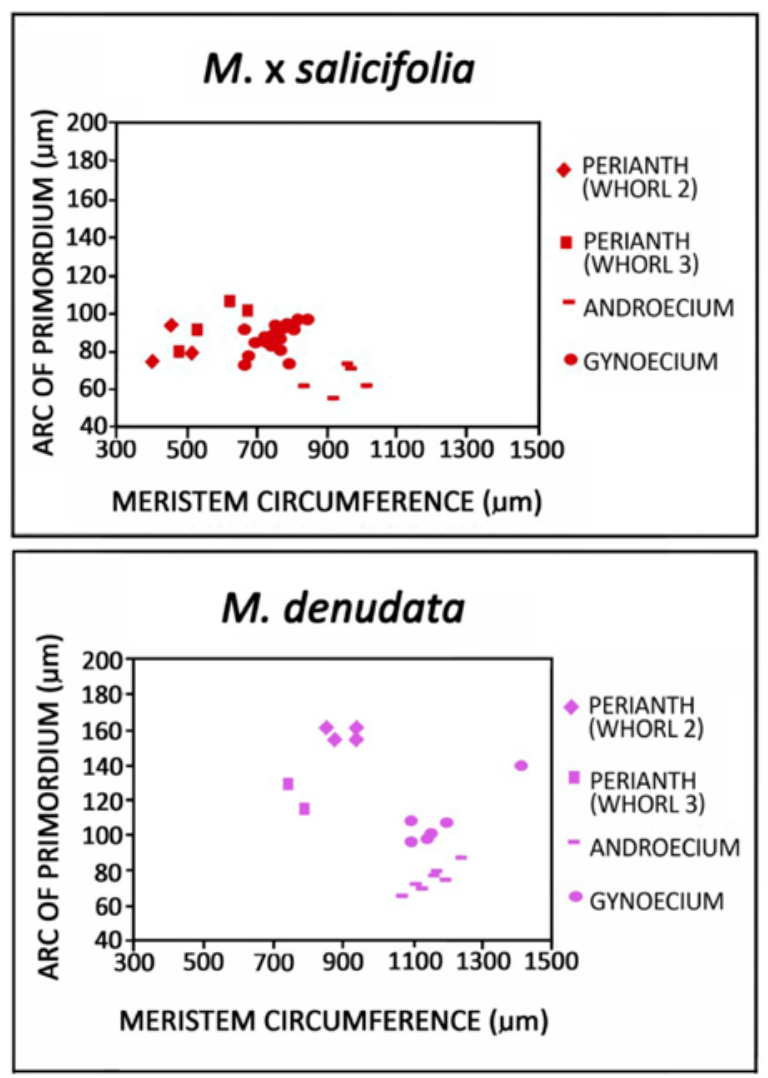

M. stellata
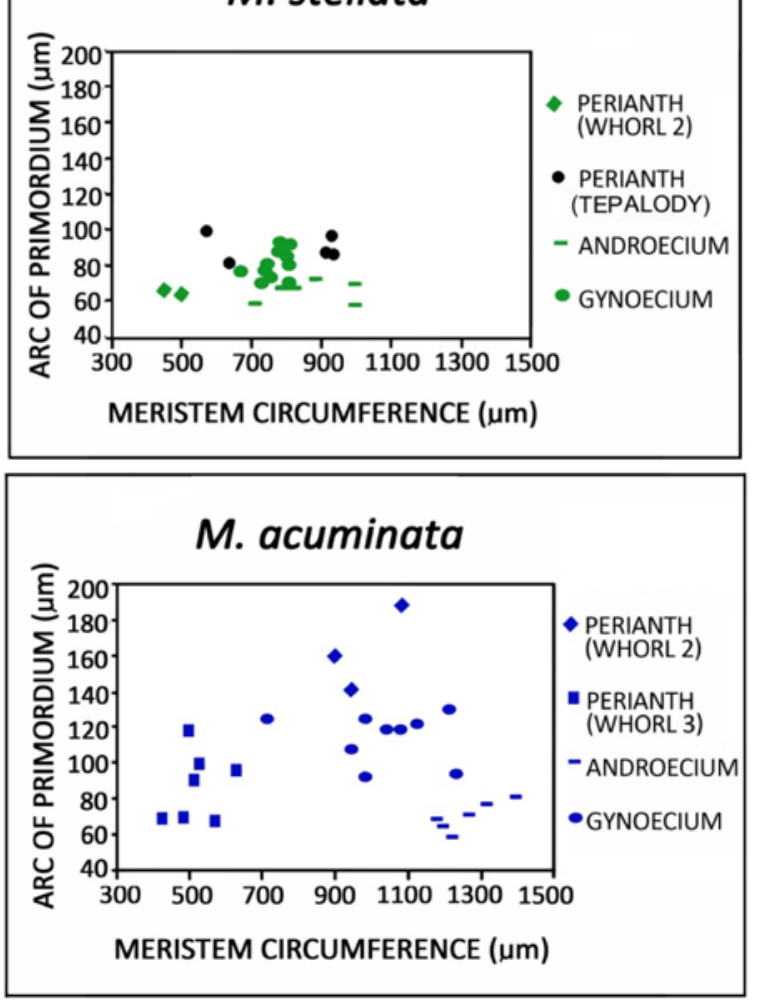

Fig. 5 The circumference of the meristem and its arc occupied by lateral organ primordium in the successive floral zones of analysed magnolias. Detailed description in the text.

sample contained $N=20$ meristems). At mean values $M=$ $742.49 \mu \mathrm{m}$ and $P=87.1 \mu \mathrm{m}$ (Fig. 5, Tab. 2) the most probable values of parameter $A$ ranged between $36.25^{\circ}$ and $49.31^{\circ}$ (Tab. 3). Angles $\beta$ were usually close to $105^{\circ}(N=10)$, in few cases close to $90^{\circ}$ or $75^{\circ}$ (in both cases $N=4$ ) and the most rarely to $120^{\circ}(N=2$; Tab. 3). Comparison of empirical data with theoretical values $A$ accounted for the occurrence of patterns 5:8, 4:7 and 4:6 in gynoecia of this specimen but also indicated, that patterns 5:7 and 6:9, never noted as pure ones, should have been initiated as often as dominating Fibonacci pattern.

Meristems of $M$. stellata, which initiated from 14 to 34 primordia $(N=15)$, were slightly larger (mean $M=765.85 \mu \mathrm{m})$ while their primordia were smaller (mean value of $P=81.72$ $\mu \mathrm{m}$ ) compared to $M . \times$ salicifolia (Fig. 5, Tab. 2). The range of estimated values $A-33.24^{\circ}-42.06^{\circ}$ at the most common angle $\beta=90^{\circ}(N=6)$, similarly like in the case of $M . \times$ salicifolia, suggested occurrence of patterns 5:8, 6:9 and 5:7 as the most common in $M$. stellata gynoecia. According to theoretical data main Fibonacci bijugy, noted as the second pattern in frequency should have occurred only at rare angle $\beta=105(N$ $=3$ ) and should not be more often than Lucas pattern, which was predicted to occur only when angle $\beta$ is close to $75^{\circ}(N=$ 3). Although all examined specimens had similar numbers of parastichies in gynoecia, $M$. denudata and $M$. acuminata had noticeably larger primordia and meristems than $M . \times$ salicifolia and M. stellata.

Only 6 meristems, at the stage of initiation from 10th to 22nd carpel primordium, were examined in M. denudata. Unlike the meristems of the other specimens, meristems of
$M$. denudata initiating carpels were larger (mean value of $M=1178.77 \mu \mathrm{m}$ ) than the meristems initiating stamens but the carpel primordia were typically larger (mean value of $P=$ $109.1 \mu \mathrm{m}$ ) than the stamen primordia (Fig. 5, Tab. 2). Wide spectrum of estimated values $A$ - between $25.8^{\circ}$ and $42.51^{\circ}$, the high variation of parameters $P$ and $M$ (Tab. 2) and variable values of angle $\beta$ (two meristems with angle $\beta=60^{\circ}$, two with angle $\beta=75^{\circ}$ and single meristems with $\beta=90^{\circ}$ and $105^{\circ}$ were found) theoretically guaranteed the occurrence of many different phyllotactic patterns. However, according to theoretical data main Fibonacci bijugy (4:6) and Fibonacci trijugy (6:9) should have occurred as the most frequent patterns in gynoecia of this specimen.

Meristems of M. acuminata were analysed at different stages between initiation of the 22nd to 35th carpel primordium ( $N$ $=9$ meristems). The mean value of $M$ was equal to $1033.11 \mu \mathrm{m}$ and had the highest variation $(V=15.18 \%)$ among examined specimens (Tab. 2). M. acuminata had also the largest carpel primordia with mean $P=114.94 \mu \mathrm{m}$ (Fig. 5, Tab. 2). The wide range of estimated values $A$ - from $30.72^{\circ}$ to $52.71^{\circ}$, and variable angles $\beta$ ( 4 meristems with angle $\beta=90^{\circ}$, 2 with $\beta=75^{\circ}$ and $105^{\circ}$ and single with $\beta=60^{\circ}$ ) explained the wide spectrum of phyllotactic patterns. Nonetheless, like for the other specimens a comparison of empirical data with theoretical values $A$ indicated that frequency of particular patterns should have been different than identified one - patterns 5:8, 5:7 and 4:7 should have occurred as the most common and in equal frequencies in M. acuminata gynoecia.

Some features, like the size of the meristem and primordia in gynoecium zone, were similar for $M . \times$ salicifolia and $M$. 
Tab. 3 The ranges of parameter $P$ and $M$ values (calculated taking into account their mean values and standard deviations), estimated values of parameter $A$ and angles $\beta$ in androecia and gynoecia of examined flowers.

\begin{tabular}{|c|c|c|c|c|c|}
\hline Genet & The zone of flower & $M, P$ & Range of $M$ and $P$ & Parameter $A$ & Angle $\beta$ \\
\hline \multirow[t]{4}{*}{ M. $\times$ salicifolia } & Androecium & $M$ & $870.97-1007.39$ & $20.35^{\circ}-30.23^{\circ}$ & $60^{\circ}-105^{\circ}$ \\
\hline & & $P$ & $56.95-73.14$ & & \\
\hline & Gynoecium & $M$ & $690.91-794.06$ & $36.25^{\circ}-49.31^{\circ}$ & $75^{\circ}-120^{\circ}$ \\
\hline & & $P$ & 79.97-94.64 & & \\
\hline \multirow[t]{4}{*}{ M. stellata } & Androecium & $M$ & $749.41-980.57$ & $21.96^{\circ}-34.35^{\circ}$ & $75^{\circ}-90^{\circ}$ \\
\hline & & $P$ & $59.83-71.52$ & & \\
\hline & Gynoecium & $M$ & $762.14-805.56$ & $33.24^{\circ}-42.06^{\circ}$ & $75^{\circ}-120^{\circ}$ \\
\hline & & $P$ & $74.39-89.05$ & & \\
\hline \multirow[t]{4}{*}{ M. denudata } & Androecium & $M$ & $1095.32-1204.56$ & $20.4^{\circ}-27.1^{\circ}$ & $90^{\circ}$ \\
\hline & & $P$ & $68.28-82.48$ & & \\
\hline & Gynoecium & $M$ & $1059.98-1297.56$ & $25.8^{\circ}-42.51^{\circ}$ & $60^{\circ}-105^{\circ}$ \\
\hline & & $P$ & $93.01-125.19$ & & \\
\hline \multirow[t]{4}{*}{ M. acuminata } & Androecium & $M$ & $1181.04-1344.18$ & $16.77^{\circ}-23.77^{\circ}$ & $75^{\circ}-90^{\circ}$ \\
\hline & & $P$ & $62.63-78.01$ & & \\
\hline & Gynoecium & $M$ & $876.21-1190.01$ & $30.72^{\circ}-52.71^{\circ}$ & $60^{\circ}-105^{\circ}$ \\
\hline & & $P$ & $101.57-128.31$ & & \\
\hline
\end{tabular}

stellata and distinguished them from M. denudata and M. acuminata. The last two genets, as opposed to M. $\times$ salicifolia and M. stellata, did not have common expressions of phyllotactic patterns in gynoecium and androecium zone (Fig. 4). This suggested that the value of parameter $A$ was changing more drastically between androecium and gynoecium zone in $M$. denudata and $M$. acuminata. Examination of transverse sections of the meristems in all specimens, and also longitudinal sections of $M . \times$ salicifolia and M. acuminata showed, that in every case the change in the meristem size after the switch from initiating stamens to carpels occurred gradually. Thus, the drastic change in the parameter $A$ value between androecium and gynoecium zone in $M$. denudata and M. acuminata was probably caused by abrupt change in the size of initiated primordia between those two zones.

\section{Discussion}

During ontogeny of Magnolia flower the changes in the initiated organ identity are accompanied by the changes in the meristem and primordia sizes and alterations in organ arrangement. Typically whorled pattern of perianth transforms into spiral pattern of androecium, which is subsequently replaced by a new spiral pattern of gynoecium. Our study revealed that the range of the meristem and primordia sizes in successive zones of the flower is characteristic for the selected individual trees. However, the significance of these geometrical parameters in determination of characteristic phyllotactic spectra differs in successive zones of the flower.

The most stable part of the analysed Magnolia flowers is perianth, where relatively large tepals are asymmetrically distributed around meristem circumference in three trimerous whorls. The distribution and unequal sizes of the elements may suggest that they in fact are initiated spirally in the sequence of very short plastochrones. Such mechanism of the perianth initiation was noted earlier in $M$. denudata [53] and in some other plants [54-58]. The rare discrepancies from the basic trimerous pattern of the perianth initiation include: $(\boldsymbol{i})$ tetramerous whorls in M. $\times$ salicifolia; $(\boldsymbol{i i})$ the element missing in the predicted position of the whorl in $M$. stellata or (iii) initiation of two elements instead of one in $M$. $\times$ salicifolia. Similar anomalies were identified in M. acuminata gynoecia, where lack or occurrence of additional elements was noted within spiral pattern, in the course of single parastichy [59]. Clearly spiral mode of tepals initiation was observed in $M$. stellata where perianth elements develop in the region topologically belonging to androecium on meristems which are larger than in the zone of trimerous pattern. Variations in magnolia perianth discussed recently by Zagórska-Marek [60] may provide an additional clues on genetic regulation of the identity and distribution of floral structures by homeotic genes.

In the development of Magnolia flower relatively large meristems initiating small primordia, yielding low values of $P / M$ ratio, are specific for androecium. Our analysis revealed exceptional richness of spiral phyllotactic patterns with high numbers of parastichies in this zone. In contrast to our results, Erbar and Leins [61] identified usually eight and rarely seven or nine parastichies on meristems of $M$. stellata initiating stamens and carpels. However, their method of pattern identification, based on estimation of the number of parastichies in one chiral group only, was incorrect. Eight parastichies in one of two chiral groups can be ascribed to the Fibonacci pattern as well as to the pattern $8: 11$, similarly seven parastichies can be ascribed to Lucas pattern but also to the pattern 7:10. Although rare, and even considered as non-existing [62], patterns 8:11 and 7:10 were identified in the course of present analysis - in androecia of $M . \times$ salicifolia and M. stellata, and earlier in vegetative development of Abies balsamea [10], Pinus mugo [63] and Rebutia cacti [64]. Phyllotactic spectra in Magnolia androecia are significantly enriched by qualitative transformations, occurring very often even in single meristems. Two alternative mechanisms have been proposed as underlying phyllotactic transformations. Transition of one pattern into another can result from the local fluctuations of growth on the meristem circumference $[16,17]$, or can be induced by gradual changes affecting the growth along the whole meristem circumference [26-28,31,65]. Although we cannot predict, which of those 
Tab. 4 Phyllotactic patterns and their transformations identified in the gynoecia of embryonic shoots.

\begin{tabular}{|c|c|c|c|c|c|c|c|}
\hline Genet & Season & Pattern & $S$ & $\mathbf{Z}$ & Transformations & $N$ & $\mathrm{Z} / \mathrm{S} \rightarrow \mathrm{S} / \mathrm{Z}$ \\
\hline \multirow[t]{10}{*}{ Magnolia salicifolia } & $2000-2001$ & $5: 8$ & 166 & 174 & $5 z: 8 s \rightarrow 4 z: 6 s$ & 1 & - \\
\hline & & $4: 7$ & 26 & 28 & $4 \mathrm{z}: 7 \mathrm{~s} \rightarrow 4 \mathrm{z}: 6 \mathrm{~s}$ & 2 & + \\
\hline & & $4: 6$ & 4 & 9 & $5 z: 7 s \rightarrow 4 z: 6 s$ & 1 & + \\
\hline & & & & & $5 z: 7 s \rightarrow 4 z: 7 s$ & 2 & - \\
\hline & & & & & $4 s: 6 z \rightarrow 4 s: 5 z$ & 1 & - \\
\hline & 2001-2002 & $5: 8$ & 128 & 90 & $6 z: 9 s \rightarrow 5 z: 8 s$ & 1 & - \\
\hline & & $4: 7$ & 14 & 15 & $5 \mathrm{z}: 8 \mathrm{~s} \rightarrow 4 \mathrm{z}: 7 \mathrm{~s} \rightarrow 5 \mathrm{z}: 8 \mathrm{~s}$ & 2 & $-1+$ \\
\hline & & $4: 6$ & 9 & 5 & $4 \mathrm{z}: 7 \mathrm{~s} \rightarrow 4 \mathrm{z}: 6 \mathrm{~s}$ & 1 & + \\
\hline & & & & & $5 z: 7 s \rightarrow 4 z: 6 s$ & 1 & + \\
\hline & & & & & $4 s: 8 z \rightarrow 4 s: 7 z$ & 1 & - \\
\hline \multirow[t]{11}{*}{ Magnolia stellata } & 2001-2002 & $6: 8$ & - & 1 & $4 \mathrm{z}: 7 \mathrm{~s} \rightarrow 4 \mathrm{z}: 6 \mathrm{~s}$ & 2 & + \\
\hline & & $5: 8$ & 55 & 45 & $5 \mathrm{~s}: 7 \mathrm{z} \rightarrow 4 \mathrm{~s}: 7 \mathrm{z}$ & 1 & - \\
\hline & & $5: 7$ & - & 1 & $6 \mathrm{z}: 9 \mathrm{~s} \rightarrow 5 \mathrm{z}: 8 \mathrm{~s}$ & 1 & - \\
\hline & & $4: 7$ & 1 & - & $4 z: 6 s \rightarrow 4 z: 5 s$ & 1 & - \\
\hline & & $4: 6$ & 4 & 4 & & & + \\
\hline & $2002-2003$ & $6: 9$ & 1 & 3 & $5 \mathrm{~s}: 8 \mathrm{z} \rightarrow 5 \mathrm{~s}: 7 \mathrm{z} \rightarrow 4 \mathrm{~s}: 7 \mathrm{z}$ & 1 & $+1-$ \\
\hline & & $5: 9$ & 1 & 1 & $4 z: 6 s \rightarrow 3 z: 6 s$ & 1 & + \\
\hline & & $5: 8$ & 50 & 85 & $4 z: 8 s \rightarrow 4 z: 7 s$ & 1 & - \\
\hline & & $5: 7$ & 3 & 1 & $6 z: 7 s \rightarrow 4 z: 8 s$ & 1 & + \\
\hline & & $4: 7$ & 1 & 1 & & & \\
\hline & & $4: 6$ & 14 & 11 & & & \\
\hline \multirow[t]{10}{*}{ Magnolia denudata } & 2001-2002 & $6: 9$ & 1 & 2 & $5 s: 8 z \rightarrow 4 s: 8 z$ & 1 & + \\
\hline & & $5: 8$ & 46 & 31 & & & \\
\hline & & $5: 7$ & - & 1 & & & \\
\hline & & $4: 7$ & 1 & 1 & & & \\
\hline & & $4: 6$ & 2 & 2 & & & \\
\hline & $2002-2003$ & $6: 9$ & - & 3 & $5 \mathrm{~s}: 7 \mathrm{z} \rightarrow 5 \mathrm{~s}: 8 \mathrm{z}$ & 1 & + \\
\hline & & $5: 8$ & 64 & 72 & $6 \mathrm{z}: 7 \mathrm{~s} \rightarrow 5 \mathrm{z}: 7 \mathrm{~s} \rightarrow 4 \mathrm{z}: 6 \mathrm{~s}$ & 1 & $+/+$ \\
\hline & & $5: 7$ & 6 & 3 & & & \\
\hline & & $4: 7$ & 2 & 4 & & & \\
\hline & & $4: 6$ & 4 & 1 & & & \\
\hline \multirow[t]{7}{*}{ Magnolia acuminata } & 2004 & $6: 9$ & 4 & 5 & & & \\
\hline & & $6: 7$ & - & 1 & & & \\
\hline & & $5: 8$ & 19 & 18 & & & \\
\hline & & $5: 7$ & 5 & 5 & & & \\
\hline & & $4: 8$ & - & 1 & & & \\
\hline & & $4: 7$ & 5 & 4 & & & \\
\hline & & $4: 6$ & 3 & 7 & & & \\
\hline
\end{tabular}

In three of four genets the data were collected for two consecutive seasons. The $\mathrm{S}$ and $\mathrm{Z}$ configurations of ontogenetic helix for each pattern were distinguished and the number of cases in each class counted. In case of transformations it was noted if they occurred with (+) or without $(-)$ a change in the direction of ontogenetic helix.

mechanisms is the most adequate for explanation of changing phyllotaxis in Magnolia androecia, we can expect that fluctuations of growth affecting meristem and/or primordia size are considerable at this stage of floral ontogeny.

Geometrical models of phyllotaxis [1-5] [see also Iterson (1907; cited in [5])] assume, that the potential of meristems to initiate stable or variable patterns should be reflected in the degree of variation in the meristem and primordia sizes. Variation of the meristem size is decisive for the variability of whorled patterns in vegetative development of Hippuris [66], Equisetum [67] and whorled and spiral patterns in Sedum maximum [68]. In abphyl1 mutants of maize alteration of phyllotaxis, from distichous to decussate pattern, is accompanied by changes in the size of vegetative meristem and initiated primordia of leaves [69-71]. High diversity of phyllotaxis in Magnolia androecia is similarly guaranteed by considerable variation of both parameters - meristem and primordia sizes. Additionally all examined specimens, except $M$. denudata, have the variable angles of parastichy intersection in this zone. Constancy of the angles of parastichy intersection, reflecting stable mode of primordia packing, may condition slight preference towards initiation of stamens in pure Fibonacci pattern in M. denudata.

The development of generative meristems producing flowers is determinate, what means that their activity decreases and eventually ceases with the initiation of the last primordium [72]. Genetic mechanism inducing determinate state of the meristem can be triggered at different stages of generative 
development [36,73]. In M. × salicifolia, M. stellata and $M$. acuminata flowers such developmental switch probably occurs together with the change in the identity of initiated primordia from stamens to carpels, when the mean value of the meristem size decreases comparing to that in preceding stage of organogenesis. Similar reduction in the meristem size, occurring concurrently with the beginning of carpels initiation, was noted in Michelia fuscata [54]. In M. denudata the early stages of gynoecium formation are concomitant with further increase in the mean value of the meristem size. This implies that the determinate mechanism of the meristem growth may be induced in the flowers of this specimen relatively late - after the initiation of certain defined number of carpels, similarly like in Ranunculus [56]. Because the measurements of analysed geometrical parameters were taken at various stages of androecium and gynoecium development mean values of the meristem and primordia sizes do not inform how exactly these parameters change during ontogeny of a single flower. The change in the $P / M$ ratio between androecium and gynoecium probably always has quite drastic character in $M$. denudata and $M$. acuminata meristems which, as opposed to $M . \times$ salicifolia and $M$. stellata, never initiate patterns with common numbers of parastichies in these two zones. Our analysis suggests that drastic alterations in $P / M$ ratio values are caused by abrupt increase in the primordia size at the beginning of carpel initiation while the changes in the size of the meristem occur gradually. Quite clear visual change in primordia size in a generative part of the floral axis of Magnolia acuminata at the time of transition from initiating stamens into carpels has already been documented on scanning electron microscopic images [12].

In gynoecia of all examined magnolias the main Fibonacci pattern dominates but its frequency, as well as the occurrence and frequency of additional patterns are genet-specific. Some of the additional patterns were noted as exclusively accompanying qualitative transformations, but they did not broaden phyllotactic spectra to the extent observed in the androecium zone, where transformations are particularly frequent. Examination of patterns in gynoecia of $M . \times$ salicifolia and $M$. stellata confirmed the results of earlier analysis performed for the same trees [12] - as the second in frequency $M . \times$ salicifolia initiated Lucas pattern while M. stellata the main Fibonacci bijugy. Among additional patterns identified in $M$. denudata and M. acuminata none was markedly more frequent than others. Previous analysis of gynoecia patterns, conducted in other genets of these species [12], indicated much greater diversity of phyllotaxis in $M$. denudata and significant intraspecific variation of phyllotactic spectra in M. acuminata. Depending on a tree, gynoecia of $M$. acuminata exhibited dominance of either Fibonacci pattern or others like main Fibonacci bijugy or even trijugy [12].

Four genets examined in this study differ in the meristem and primordia sizes, determining specific ranges of $P / M$ ratio, and in the degree of variation of the angles of parastichy intersection in gynoecia. The values of these parameters suggest slightly different phyllotactic spectra than those identified and quite different frequencies of the patterns. This implies that the arrangement of primordia on the meristem surface, at least in Magnolia gynoecia, depends not only on the ratio of the organ size to the size of the meristem, but also on other geometric factors, or factors of different than purely geometrical nature.

It has been shown in computer simulations that geometrical parameters of the initial pattern in the perianth and the way in which the $P / M$ ratio evolves during flower ontogeny, are important for the quality and stability of phyllotaxis in Magnolia gynoecium [31]. The importance of the initial pattern for the arrangement of newly initiated primordia have been demonstrated for many plant systems $[10,74-76]$ or systems generated in computer simulations [27,28]. It is also supported by our observation, that patterns frequently noted in gynoecia are often initiated in continuity with the same pattern in androecium zone, while uncommon patterns of gynoecia are preceded by patterns of androecia regarded as rare in nature. On this basis we can explain why examined tree of $M$. denudata has less variable phyllotaxis of gynoecia, than suggested by the analysis of the ratio $P / M$ or former analysis of patterns in gynoecia of the other specimen of this species [12]. It is probable that stamens, which in this specimen are often initiated in pure Fibonacci pattern, exert stabilising influence on the positioning of carpel primordia and restrict the number of their possible arrangements. This stabilising effect can be additionally enhanced by relatively late shift from indeterminate to determinate growth of the meristem, what excludes potential fluctuations of growth in the early stages of gynoecium pattern formation. In the recent theoretical study it has been shown that phyllotactic patterns differ in their developmental stability and that the Fibonacci pattern and its bijugy are the most stable [65]. This might explain the persistence of these prevailing patterns in a course of initiation of generative parts on the magnolia floral axis.

All these theoretical considerations are based on the assumption of the autonomy of apical meristem generating certain, defined organographic order. Numerous data implicate though, that meristems act as non-autonomous organogenic centres, in which initiation process is guided by the signals flowing acropetally from differentiated tissues of the stem. Primary vascular system is proposed as developmental blueprint for primordia positioning, based on interrelationship between lateral organ arrangement and vascular architecture demonstrated in many plants $[6,7,14,77,78]$. Although the exact mechanism of the interaction between these two systems and the nature of the signalling molecule mediating between them remain undefined, there are some new exciting data on PIN1 mutants of Arabidopsis thaliana suggesting possible role of auxin transported acropetally in provascular strands [9]. In vegetative development of Torreya the degree of meristem autonomy most probably changes with the identity of primordia - bijugate pattern of the needles is determined by differentiating protoxylem, but bud scales are initiated in decussate pattern independently of any signal from differentiated tissues [8]. It is possible that the degree of meristem autonomy changes also in the development of Magnolia flower. Our analysis suggests that the arrangement of stamens is dictated by purely geometrical clues - the size of primordia relative to the meristem size and the angle of parastichies intersection. In gynoecia the ratio $P / M$ determine only the general number of parastichies but exact spectra and frequencies of initiated patterns seem to be specified either by the way in which this parameters evolve from the beginning of the flower ontogeny or by the signals flowing from primary vascular system, as suggested by the first symptoms of primordium initiation (mitoses of the first periclinal divisions) taking place beneath L2 layer of the floral apex (Fig. 3). First scenario can be verified by use of computer simulation, the second through the analysis of the relationship between development of organ primordia and corresponding vascular traces. Both approaches were beyond the scope of our analysis and are awaiting further studies. 


\section{Acknowledgements}

This research is a part of the $\mathrm{PhD}$ Thesis of the first author, presented to the Faculty of Biological Sciences at the University of Wrocław, Poland.

\section{References}

1. Church AH. On the relation of phyllotaxis to mechanical laws. London: Williams \& Norgate; 1904.

2. Richards FJ. The geometry of phyllotaxis and its origin. Symp Soc Exper Biol. 1948;2:217-245.

3. Richards FJ. Phyllotaxis: its quantitative expression and relation to growth in the apex. Phil Trans R Soc B. 1951;235(629):509-564. http://dx.doi.org/10.1098/ rstb.1951.0007

4. Richards FJ. Spatial and temporal correlations involved in leaf pattern production at the apex. In: Milthrope FL, editor. The growth of leaves. London: Butterworths; 1956. p. 66-76.

5. Erickson RO. The geometry in phyllotaxis. In: Dale JE, Milthorpe FL, editors. The growth and functioning of leaves: proceedings of a symposium held prior to the thirteenth International Botanical Congress at the University of Sydney, 18-20 August 1981. Cambridge: Cambridge University Press; 1983. p. 53-88.

6. Larson PR. Development and organization of the primary vascular system in Populus deltoides according to phyllotaxy. Am J Bot. 1975;62(10):1084-1099. http://dx.doi. org/10.2307/2442125

7. Larson PR. Phyllotactic transitions in the vascular system of Populus deltoides Bartr. as determined by ${ }^{14} \mathrm{C}$ labeling. Planta. 1977;134(3):241-249. http://dx.doi.org/10.1007/ BF00384188

8. Banasiak A, Zagórska-Marek B. Signals flowing from mature tissues to SAM determine the phyllotactic continuity in successive annual increments of the conifer shoot. Acta Soc Bot Pol. 2006;75(2):113-121.

9. Banasiak A. Putative dual pathway of auxin transport in organogenesis of Arabidopsis. Planta. 2011;233(1):49-61. http://dx.doi.org/10.1007/s00425-010-1280-0

10. Zagórska-Marek B. Phyllotactic patterns and transitions in Abies balsamea. Can J Bot. 1985;63(10):1844-1854. http:// dx.doi.org/10.1139/b85-259

11. Szymanowska-Pułka M. Phyllotactic patterns in capitula of Carlina acaulis L. Acta Soc Bot Pol. 1994;65(3-4):229-245. http://dx.doi.org/10.5586/asbp.2011.043

12. Zagórska-Marek B. Phyllotaxic diversity in Magnolia flowers. Acta Soc Bot Pol. 1994;63(2):117-137.

13. Endress P. Floral phyllotaxis and floral evolution. Bot Jahrb Syst. 1987;108(2-3):417-438. http://dx.doi.org/10.1016/j. pbi.2006.11.007

14. Tucker SC. Phyllotaxis and vascular organization of the carpels in Michelia fuscata. Am J Bot. 1961;48(1):60. http:// dx.doi.org/10.2307/2439596

15. Doust AN. The developmental basis of floral variation in Drimys winteri (Winteraceae). Int J Plant Sci. 2001;164(4):697-717.

16. Zagórska-Marek B. Phyllotaxis triangular unit: phyllotactic transitions as the consequence of apical wedge disclinations in a crystal-like pattern of the units. Acta Soc Bot Pol. 1987;56(2):229-255.
17. Meicenheimer RD, Zagórska-Marek B. Consideration of the geometry of the phyllotaxic triangular unit and discontinuous phyllotactic transitions. J Theor Biol. 1989;139(3):359368. http://dx.doi.org/10.1016/S0022-5193(89)80214-0

18. Gomez-Campo C. Phyllotactic patterns in Bryophyllum tubiflorum Harv. Bot Gaz. 1974;135(1):49-58.

19. Gola EM. Phyllotaxis diversity in Lycopodium clavatum L. and Lycopodium annotinum L. Acta Soc Bot Pol. 1996;65(3-4):235-247.

20. Kwiatkowska D. Intraspecific variation of phyllotaxis stability in Anagallis arvensis. Acta Soc Bot Pol. 1997;66(3-4):259-271.

21. Stieger PA, Reinhardt D, Kuhlemeier C. The auxin influx carrier is essential for correct leaf positioning. Plant J. 2002;32(4):509-517. http://dx.doi. org/10.1046/j.1365-313X.2002.01448.x

22. Reinhardt D, Pesce ER, Stieger P, Mandel T, Baltensperger $\mathrm{K}$, Bennett M, et al. Regulation of phyllotaxis by polar auxin transport. Nature. 2003;426(6964):255-260. http://dx.doi. org/10.1038/nature02081

23. Bainbridge K, Guyomarc'h S, Bayer E, Swarup R, Bennett M, Mandel T, et al. Auxin influx carriers stabilize phyllotactic patterning. Genes Dev. 2008;22(6):810-823. http:// dx.doi.org/10.1101/gad.462608

24. Veen AH, Lindenmayer A. Diffusion mechanism for phyllotaxis: theoretical physico-chemical and computer study. Plant Physiol. 1977;60(1):127-139. http://dx.doi. org/10.1104/pp.60.1.127

25. Williams RF, Brittain EG. A geometrical model of phyllotaxis. Aust J Bot. 1984;32(1):43. http://dx.doi.org/10.1071/ BT9840043

26. Douady S, Couder Y. Phyllotaxis as a dynamical self organizing process part I: the spiral modes resulting from time-periodic iterations. J Theor Biol. 1996;178(3):255-273. http://dx.doi.org/10.1006/jtbi.1996.0024

27. Douady S, Couder Y. Phyllotaxis as a dynamical self organizing process part II: the spontaneous formation of a periodicity and the coexistence of spiral and whorled patterns. J Theor Biol. 1996;178(3):275-294. http://dx.doi. org/10.1006/jtbi.1996.0025

28. Douady S, Couder Y. Phyllotaxis as a dynamical self organizing process part III: the simulation of the transient regimes of ontogeny. J Theor Biol. 1996;178(3):295-312. http://dx.doi.org/10.1006/jtbi.1996.0026

29. Jonsson H, Heisler MG, Shapiro BE, Meyerowitz EM, Mjolsness E. An auxin-driven polarized transport model for phyllotaxis. Proc Natl Acad Sci USA. 2006;103(5):16331638. http://dx.doi.org/10.1073/pnas.0509839103

30. Smith RS, Guyomarc'h S, Mandel T, Reinhardt D, Kuhlemeier C, Prusinkiewicz P. A plausible model of phyllotaxis. Proc Natl Acad Sci USA. 2006;103(5):1301-1306. http:// dx.doi.org/10.1073/pnas.0510457103

31. Zagórska-Marek B, Szpak M. Virtual phyllotaxis and real plant model cases. Funct Plant Biol. 2008;35(10):10251033. http://dx.doi.org/10.1071/FP08076

32. Snow M, Snow R. Auxin and leaf formation. New Phytol. 1937;36(1):1-18. http://dx.doi. org/10.1111/j.1469-8137.1937.tb06899.x

33. Snow M, Snow R. Minimum areas and leaf determination. Proc R Soc B. 1952;139(897):545-566. http://dx.doi. org/10.1098/rspb.1952.0034

34. Snow M, Snow R. Regulation of sizes of leaf primordia by growing-point of stem apex. Proc R Soc B. 
1955;144(915):222-229. http://dx.doi.org/10.1098/ rspb.1955.0053

35. Lenhard M, Laux T. Stem cell homeostasis in the Arabidopsis shoot meristem is regulated by intercellular movement of CLAVATA3 and its sequestration by CLAVATA1. Development. 2003;130:3163-3173. http://dx.doi.org/10.1242/ dev.00525

36. Sharma VK, Carles CC, Fletcher JC. Maintenance of stem cell populations in plants. Proc Natl Acad Sci USA. 2003;100(90001):11823-11829. http://dx.doi.org/10.1073/ pnas. 1834206100

37. Zhao Y, Medrano L, Ohashi K, Fletcher JC, Yu H, Sakai H, et al. HANABA TARANU is a GATA transcription factor that regulates shoot apical meristem and flower development in Arabidopsis. Plant Cell. 2004;16(10):2586-2600. http://dx.doi.org/10.1105/tpc.104.024869

38. Hu Y, Xie Q, Chua NH. The Arabidopsis auxin-inducible gene ARGOS controls lateral organ size. Plant Cell. 2003;15(9):1951-1961. http://dx.doi.org/10.1105/ tpc. 013557

39. Ori N, Eshed Y, Chuck G, Bowman JL, Hake S. Mechanisms that control knox gene expression in the Arabidopsis shoot. Development. 2000;127(24):5523-5532.

40. Semiarti E, Ueno Y, Tsukaya H, Iwakawa H, Machida C, Machida Y. The ASYMMETRIC LEAVES2 gene of Arabidopsis thaliana regulates formation of a symmetric lamina, establishment of venation and repression of meristem-related homeobox genes in leaves. Development. 2001;128(10):1771-1783.

41. Autran D, Jonak C, Belcram K, Beemster GTS, Kronenberger J, Grandjean O, et al. Cell numbers and leaf development in Arabidopsis: a functional analysis of the STRUWWELPETER gene. EMBO J. 2002;21(22):60366049. http://dx.doi.org/10.1093/emboj/cdf614

42. Clay NK, Nelson T. The recessive epigenetic swellmap mutation affects the expression of two step II splicing factors required for the transcription of the cell proliferation gene STRUWWELPETER and for the timing of cell cycle arrest in the Arabidopsis leaf. Plant Cell. 2005;17(7):1994-2008. http://dx.doi.org/10.1105/tpc.105.032771

43. Running MP, Fletcher JC, Meyerowitz EM. The WIGGUM gene is required for proper regulation of floral meristem size in Arabidopsis. Development. 1998;125(14):2545-2553.

44. Song JY, Leung T, Ehler LK, Wang C, Liu Z. Regulation of meristem organization and cell division by TSO1, an Arabidopsis gene with cysteine-rich repeats. Development. 2000;127(10):2207-2217.

45. Hauser BA, He JQ, Park SO, Gasser CS. TSO1 is a novel protein that modulates cytokinesis and cell expansion in Arabidopsis. Development. 2000;127(10):2219-2226.

46. Dornelas MC, van Lammeren AA, Kreis M. Arabidopsis thaliana SHAGGY-related protein kinases (AtSK11 and 12) function in perianth and gynoecium development. Plant J. 2000;21(5):419-429. http://dx.doi. org/10.1046/j.1365-313x.2000.00691.x

47. Leyser HMO, Furner IJ. Characterisation of three shoot apical meristem mutants of Arabidopsis thaliana. Development. 1992;116(2):397-403.

48. Laufs P, Dockx J, Kronenberger J, Traas J. MGOUN1 and MGOUN2: two genes required for primordium initiation at the shoot apical and floral meristems in Arabidopsis thaliana. Development. 1998;125(7):1253-1260.

49. Para A, Sundås-Larsson A. The pleiotropic mutation dar1 affects plant architecture in Arabidopsis thaliana. Dev Biol. 2003;254(2):215-225. http://dx.doi.org/10.1016/ S0012-1606(02)00035-0

50. Xu FX. Floral ontogeny of two species in Magnolia L. J Integr Plant Biol. 2006;48(10):1197-1203. http://dx.doi. org/10.1111/j.1744-7909.2006.00341.x

51. Xu F, Rudall PJ. Comparative floral anatomy and ontogeny in Magnoliaceae. Plant Syst Evol. 2006;258(1-2):1-15. http://dx.doi.org/10.1007/s00606-005-0361-1

52. Johansen DA. Plant microtechnique. New York: McGrawHill Book Co.; 1940.

53. Leins P, Erbar C. Floral developmental studies: some old and new questions. Int J Plant Sci. 1997;158(6 suppl):3-12. http://dx.doi.org/10.1086/297504

54. Tucker SC. Ontogeny of the floral apex of Michelia fuscata. Am J Bot. 1960;47(4):266. http://dx.doi. org/10.2307/2439606

55. Lyndon RF. Phyllotaxis and the initiation of primordia during flower development in Silene. Ann Bot. 1978;42:1349-1360.

56. Meicenheimer RD. Relationships between shoot growth and changing phyllotaxy of Ranunculus. Am J Bot. 1979;66(5):557. http://dx.doi.org/10.2307/2442505

57. Uhl NW, Moore HE. Androecial development in six polyandrous genera representing five major groups of palms. Ann Bot. 1980;45(1):57-75.

58. Kirchoff BK. Shape matters: Hofmeister's rule, primordium shape, and flower orientation. Int J Plant Sci. 2003;164(4):505-517. http://dx.doi.org/10.1086/375421

59. Zagórska-Marek B, Wiss D. Dislocations in the repetitive unit patterns of biological systems. In: Nation JB, editor. Formal descriptions of developing systems. Manoa: Kluwer Academic Publishers; 2003. p. 99-117.

60. Zagórska-Marek B. Magnolia flower - the living crystal. Magnolia. 2011;89:11-21.

61. Erbar C, Leins P. Zur Spirale in Magnolien-Blüten. Beitr Biol Pflanzen. 1982;56:225-241.

62. Jean RV. Phyllotaxis: a systemic study in plant morphogenesis. Cambridge: Cambridge University Press; 1994.

63. Vakarelov I. Changes in phyllotactic pattern structure in Pinus L. due to changes in altitude. In: Jean RV, Barabé D, editors. Symmetry in plants. Singapore: World Scientific; 1998. p. 213-230.

64. Gola EM. Phyllotactic spectra in cacti: Mammillaria species and some genera from Rebutia group. Acta Soc Bot Pol. 1997;66(3-4):237-257.

65. Szpak M, Zagórska-Marek B. Phyllotaxis instability exploring the depths of first available space. Acta Soc Bot Pol. 2011;80(4):279-284. http://dx.doi.org/10.5586/ asbp.2011.043

66. McCully ME, Dale HM. Variations in leaf number in Hippuris. A study of whorled phyllotaxis. Can J Bot. 1961;39(3):611-625. http://dx.doi.org/10.1139/b61-050

67. Bierhorst DW. Symmetry in Equisetum. Am J Bot. 1959;46(3):170. http://dx.doi.org/10.2307/2439274

68. Kwiatkowska D, Florek-Marwitz J. Ontogenetic variation of phyllotaxis and apex geometry in vegetative shoots of Sedum maximum (L.) Hoffm. Acta Soc Bot Pol. 1999;68(2):85-95.

69. Greyson RI, Walden DB. The ABPHYL syndrome in Zea mays. I. Arrangement, number and size of leaves. Am J Bot. 1972;59(5):466-472. http://dx.doi.org/10.2307/2441527

70. Greyson RI, Walden DB, Hume JA, Erickson RO. The 
ABPHYL syndrome in Zea mays. II. Patterns of leaf initiation and the shape of the shoot meristem. Can J Bot. 1978;56(13):1545-1550. http://dx.doi.org/10.1139/b78-183

71. Jackson D, Hake S. Control of phyllotaxy in maize by the abphyl1 gene. Development. 1999;126(2):315-323.

72. Lyndon RF. The shoot apical meristem: its growth and development. Cambridge: Cambridge University Press; 1998.

73. Carles CC, Fletcher JC. Shoot apical meristem maintenance: the art of a dynamic balance. Trends Plant Sci. 2003;8(8):394-401. http://dx.doi.org/10.1016/ S1360-1385(03)00164-X

74. Hernandez LF, Palmer JH. Regeneration of the sunflower capitulum after cylindrical wounding of the receptacle. Am J Bot. 1988;75(9):1253. http://dx.doi.org/10.2307/2444447
75. Endress P. Chaotic floral phyllotaxis and reduced perianth in Achlys (Berberidaceae). Bot Acta. 1989;102:159-163.

76. Lehmann NL, Sattler R. Irregular floral development in Calla palustris (Araceae) and the concept of homeosis. Am J Bot. 1992;79(10):1145. http://dx.doi.org/10.2307/2445214

77. Kwiatkowska D. The relationships between the primary vascular system and phyllotactic patterns of Anagallis arvensis (Primulaceae). Am J Bot. 1992;79(8):904. http:// dx.doi.org/10.2307/2445001

78. Zagórska-Marek B, Banasiak A. Related to phyllotaxis interlocked systems of vascular sympodia and cortical resin canals in Abies and Picea shoots. Acta Soc Bot Pol. 2000;69(3):165-172. 